\title{
Helicosporidia: a genomic snapshot of an early transition to parasitism
}

\author{
Yukun Sun, Jean-Francois Pombert* \\ Department of Biological and Chemical Sciences, Illinois Institute of Technology, Chicago, IL 60616, USA
}

\begin{abstract}
Helicosporidia are gut parasites of invertebrates. These achlorophyllous, non-photosynthetic green algae are the first reported to infect insects. Helicosporidia are members of the green algal class Trebouxiophyceae and are further related to the photosynthetic and non-photosynthetic genera Auxenochlorella and Prototheca, respectively, the latter of which can also turn to parasitism under opportunistic conditions. Molecular analyses suggest that Helicosporidia diverged from other photosynthetic trebouxiophytes less than 200 million years ago and that its adaptation to parasitism is therefore recent. In this minireview, we summarize the current knowledge of helicosporidian genomics. Unlike many well-known parasitic lineages, the Helicosporidium sp. organelle and nuclear genomes have lost surprisingly little in terms of coding content aside from photosynthesis-related genes. While the small size of its nuclear genome compared to other sequenced trebouxiophycean representatives suggests that Helicosporidium is going through a streamlining process, this scenario cannot be ascertained at this stage. Genome expansions and contractions have occurred independently multiple times in the green algae, and the small size of the Helicosporidium genome may reflect a lack of expansion from a lean ancestor state rather than a tendency towards reduction.
\end{abstract}

Keywords: Helicosporidium; green algae; comparative genomics; entomopathogen

\section{Introduction}

Parasitism comes in many guises, transient or obligate, extracellular or intracellular. Transient parasites are free-living or symbiotic organisms that are turning to parasitism upon a set of favorable opportunistic conditions. These organisms do not rely exclusively on parasitism for their survival nor are they always well-equipped to the task. Obligate parasites, on the other hand, cannot thrive without hosts and, by necessity, came up over the course of their evolution with the strategies and the tools to facilitate infection [1]. While the modes of action (extracellular or intracellular) and levels of specialization differ between various parasites, the goal remains the same: to benefit at the expense of the host.

The road to parasitism is littered with acquisitions and losses [2-6]. Intuitively, functions and strategies that can help avoid, disrupt or even disable the hosts' defenses are valuable targets for acquisition by parasites, even more so when their survival depends on it. What is not developed intrinsically over time can be acquired sometimes quickly by horizontal transfer of foreign genetic material. Parasites can gain new functions by capturing useful genes from their hosts (e.g. [7-10]), from co-pathogens or co-symbionts (e.g. [11,12]), from other species during transit (e.g. [13]), or from other

* Corresponding author. Email: jpombert@iit.edu

Handling Editor: Andrzej Bodył various sources (e.g. [14-17]). Conversely, functions that are no longer necessary are often discarded. This is especially true for intracellular parasites, whose switch from external to internal environments shifted many functions from necessary to accessory. Given their internalization, intracellular parasites are constantly pressured to adapt to the responses of their host(s), which in turn may lead to accelerated rates of evolution compared to their free-living relatives [18-20].

Due to their reduced and/or highly adapted nature, the physiological features of parasites are often cryptic, which hinders taxonomical classification. Two well-known examples are the malaria-causing agent Plasmodium and the once enigmatic Microsporidia, which have undergone several rounds of taxonomical revisions [21,22]. Helicosporidia, the subject of this minireview, is another protist lineage whose position within the tree of life has long remained elusive. First characterized in 1921 [23], Helicosporidians were in consequence over time classified as sporozoan, myxosporidean, fungal and protozoan parasites before their position within the green algae was first hinted at nearly 80 years later based on morphological similarities with Prototheca wickerhamii, a non-photosynthetic trebouxiophyte [24]. This affiliation was soon corroborated by molecular phylogenetic inferences based on nuclear-encoded actin and rRNA genes [25] and further confirmed with additional plastid [26,27], mitochondrial [28] and nuclear data [29-31].

Helicosporidians are the first reported green algae that infect insects $[23,24]$. These entomopathogens are found 
in the outside environment as cysts surrounded by a thin pellicle and composed of three ovoid cells wrapped within a helicoidal filamentous one [24]. The relatively small helicosporidian cysts (sometimes referred as spores in the older literature), up to $6 \mu \mathrm{m}$ wide, are ingested per os and dehisces in the host's gut at the start of the invasive stage to liberate the four cells within [32]. The long filamentous cell is then uncoiled and attaches itself to the host epithelium with the help of the barbed protuberances located at its extremities. Upon successful breach of the epithelial barrier, the ovoid cells invade the hemolymph wherein they will replicate during the vegetative stage [24]. Despite their mode of replication within insect hosts, helicosporidian vegetative cells can also be cultured in vitro on limited nutrients media suggesting that, unlike many parasites, they have retained the metabolic pathways required for saprobic growth. For more information on the morphology and lifecycle of Helicosporidia, we refer to the readers to the educated description by Boucias et al. [24] and the thorough review by Tartar [32]. In this minireview, we will focus on the genomic features of Helicosporidia.

Helicosporidians are of particular interest for our understanding of the genetic changes that occur during the gradual transition to parasitism. This lineage emerged recently and is part of a green algal lineage that encompasses free-living, symbiotic and parasitic organisms [31]. Helicosporidia are members of the trebouxiophycean order Chlorellales, whose best-known genera include Nannochloris, the type species Chlorella and the achlorophyllous Prototheca [33]. The latter has been reported to sometimes infect humans and other mammals under opportunistic conditions [34]. The Chlorellales order originated circa 350 million years ago (mya), within which the Prototheca and Chlorella genera diverged somewhere between 200 to 350 mya [35]. Helicosporidians are closely related to the genus Prototheca, but as can be seen in Fig. 1, their surprisingly fast rate of evolution renders molecular clock inferences based on 18S rDNA somewhat unreliable. Nevertheless, Helicosporidia are bound to have arisen after the late Paleozoic/early Mesozoic eras, likely within the last 200 million years or so, making them one of the youngest parasitic lineages known. In comparison, the well-known parasitic lineages from Giardia, Microsporidia and Plasmodium arose 2.2, 1.2 and 1 bya, respectively [36,37]. The recent transition from free-living to insect pathogen in Helicosporidia thus offers the opportunity to shed some light onto the early stages of parasitism in this lineage.

\section{The Helicosporidium organelle genomes are present and conserved}

Organelles are often the target of major modifications in parasites. Severe alterations to organelles can force organisms towards alternate lifestyles while changes in lifecycles can impact organelles to the point that these can become barely recognizable over time. Following internalization, the chloroplast is often victim of severe atrophy, for the capability to harness sunlight and convert it to energy is limited, if not absent within the confines of the host. Keeping a functional photosynthetic apparatus in this environment is rarely beneficial if not deleterious. In the apicomplexan
Plasmodium, the relict organelle corresponding to the plastid is so derived that it took decades before it was finally identified as a remnant of a photosynthetic organelle [38-40]. The functions encoded within have been greatly diminished and the apicoplast genome has retained a limited set of genes allowing for its replication and maintenance $[41,42]$. It is unclear, however, if the Plasmodium plastid was already reduced prior to its adaptation to parasitism or if its reduction is a consequence of its pathogenic lifestyle. The blood vessels carrying the erythrocytes that these parasites infect are iron-rich environments favorable to heme synthesis but are almost systematically shrouded in darkness, such that a photosynthetic Plasmodium species would have little reason to exist.

Not surprisingly, the entomopathogenic helicosporidians are also non-photosynthetic. Losing photosynthetic capability however, by itself, does not define a parasite. Many free-living lineages never had this ability and the loss of atmospheric $\mathrm{CO}_{2}$ fixation capability occurred independently and recurrently across many photosynthetic lineages, reverting the organisms to heterotrophy. The closest known relatives of Helicosporidia from the Prototheca genus (Fig. 1) are also non-photosynthetic and, while sometimes parasitic, they can do so only under opportunistic conditions [43]. The Helicosporidium sp. plastid genome has been streamlined to a greater extent than that of Prototheca wickerhamii (Junbiao Dai, personal communication) but not as much as that of the apicoplast from Plasmodium falciparum [27,38]. As one would expect, the Helicosporidium plastid gene losses mainly affect those associated with the fixation of atmospheric carbon dioxide, i.e. none of the genes coding for products involved in it has been retained, but it also lacks all genes coding for ATP synthases that are present in Prototheca ([27,44]; Fig. 2) and four ribosomal proteins (Rpl23, Rps2, Rps9 and Rps18) that are found in other green algae. The Helicosporidium plastid genome is compact and arrayed with a single replication origin (inferred by GC-skew analyses [27]), suggesting an optimization towards efficiency and a reduction in the amount of energy spent per replication, but it is unknown if its streamlining is still actively ongoing or if it has reached a certain equilibrium.

Modifications to the mitochondrion can also have a drastic, much more potent impact on parasites. As the principal energy factory of the cell, any evolutionary trend that leads to the loss of ATP production will severely affect the parasite and increase its host dependency. In many parasites, the mitochondrion has been severely overhauled, losing its genome in the process. Those highly reduced organelles, referred to as mitosomes or hydrogenosomes, are involved in only a few of the original mitochondrial pathways $[45,46]$. Mitosomes are involved principally in iron-sulfur cluster assembly [47] and are incapable of oxygenic respiration, such that mitosome-bearing parasites like Microsporidia or Giardia have to rely either on the alternate glycolysis and pentose phosphate pathways for ATP production or on the energy that they hitchhike from their hosts to power all of their biological functions $[45,48]$. Hydrogenosomes, like those found in Trichomonas, are similarly reduced but are further distinguished by their ability to generate molecular hydrogen [49]. 


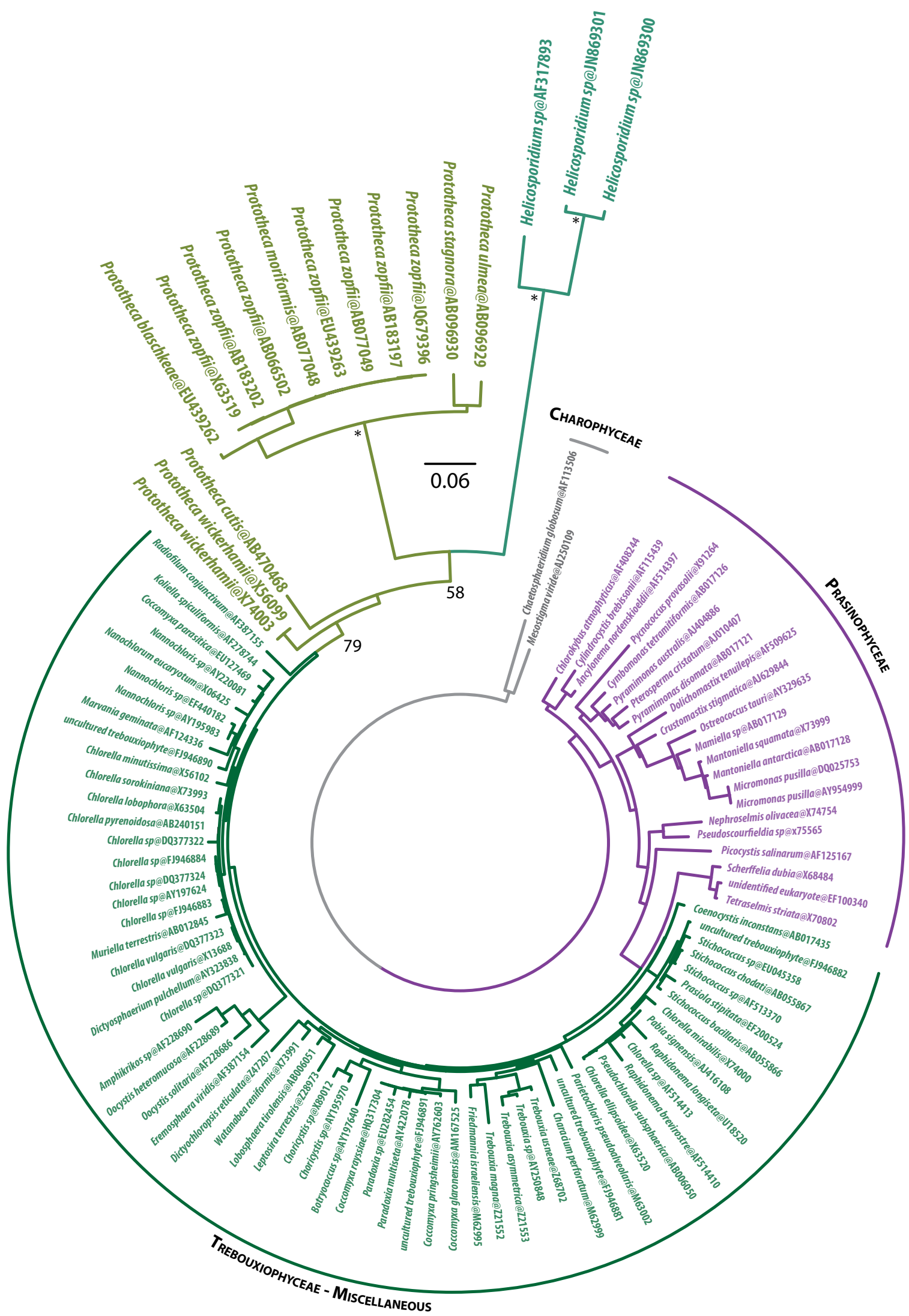

Fig. 1 Phylogenetic niche of Helicosporidium within the Trebouxiophyceae. The best $18 \mathrm{~S}$ rDNA maximum likelihood tree shown here was computed with PhyML 3.1 [62] under the general time reversible model of nucleotide substitution, as implemented in SeaView 4 [63]. The tree dataset is derived from de Wever et al. [35], to which Helicosporidium and Prototheca sequences were added. Analyses were run with and without sequences from the Ulvophyceae and Chlorophyceae (not shown), with Prasinophyceae (in purple) and the charophycean algae Mesostigma and Chaetosphaeridium (in gray) as outgroups. The Trebouxiophyceae are shown is shades of green. The grouping of Helicosporidium with Prototheca was recovered in both analyses. For brevity, the tree shown here does not include the Ulvophyceae and Chlorophyceae. Bootstrap values for the Prototheca/Helicosporidium clades above 50\% are indicated over the corresponding nodes; asterisks indicate nodes recovered in all bootstrap replicates. Branch lengths are drawn to scale. 


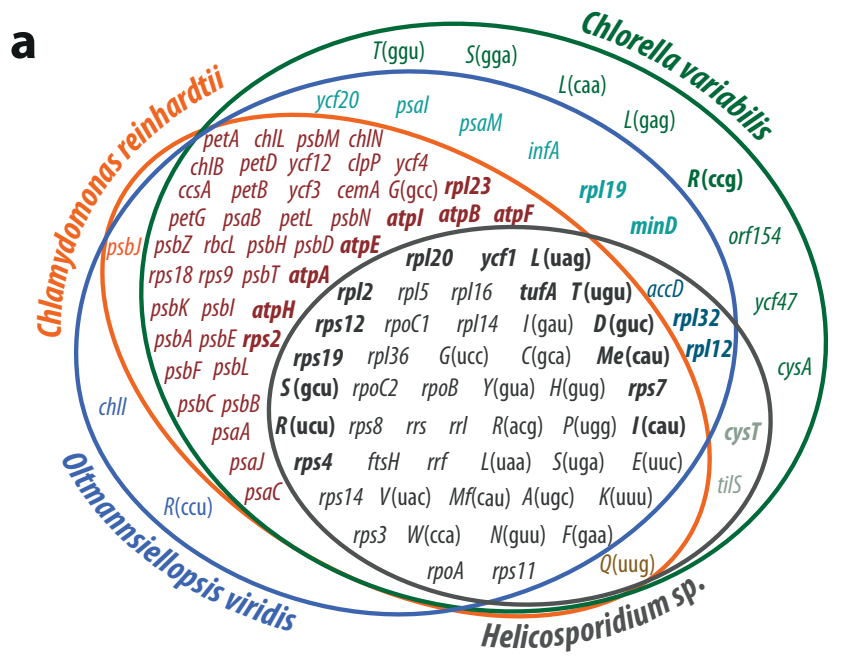

b

\section{Gene loss distribution}

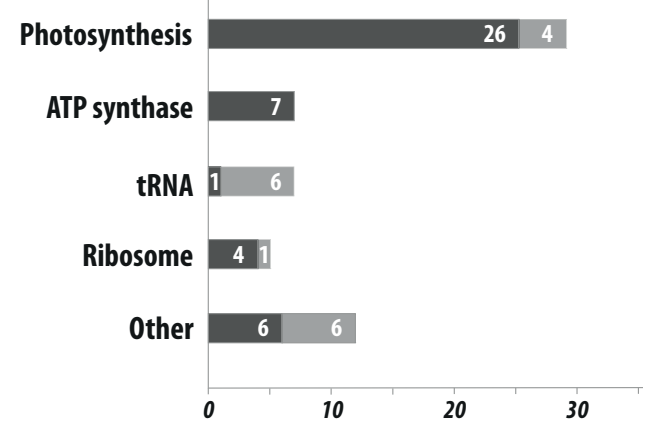

Fig. 2 Distribution of gene losses in the Helicosporidium plastid genome. a Venn representation of the genes that are shared between Helicosporidium and selected representatives of the Ulvophyceae (purple), Chlorophyceae (orange) and Trebouxiophyceae (green). Genes found in the Prototheca wickerhamii partially-sequenced plastid genome [44] are highlighted in bold. b Losses distributed by functional categories. Darker shades indicate gene losses in Helicosporidium that are shared between the Ulvophyceae, Chlorophyceae and Trebouxiophyceae (UTC). Lighter shades indicate the number of genes that are present in one or more UTC but not in Helicosporidium. None of the proteins that were lost in the Helicosporidium plastid genome were found encoded in the nucleus.

This is not the case for Helicosporidia. Helicosporidians can use oxygen as a terminal electron acceptor, as indicated by their successful growth in oxygenic conditions on nutrients-limited petri dishes [24], and have retained a mitochondrion with a full genome similar to other freeliving, early-diverging green algal lineages [28]. In fact, if we make abstraction of the Chlorophyceae, a later-diverging lineage with mid- to heavily-modified mitochondrial genomes [50], one could describe the circular, $49.3 \mathrm{kbp}$-long Helicosporidium mitochondrial chromosome as a typical green algal mitogenome. Perhaps the most salient feature in the otherwise somewhat unremarkable Helicosporidium mitochondrial genome is the presence of a trans-spliced group I intron. Trans-spliced group I introns are rare (e.g. [51] and references within) but have little to do with parasitism.

\section{The Helicosporidium nuclear genome is compact}

We often think about parasite genomes in terms of reduction, for the evolutionary pressures applied on them to stay small is intuitive, whether to facilitate replication or minimize energetic expenses. A caveat of that way of thinking is that we sometimes make involuntary shortcuts when comparing with free-living organisms. Quite often, when the genome of the parasite is smaller, we say that it has been reduced. This is true for many instances, but is it always the case? In the green algae, judging by size alone is not enough. Most genome sizes were estimated from Cvalues (Fig. 3), which are not always accurate. For example, the Ostreococcus genome was thus once estimated at around $100 \mathrm{Mbp}$ [52], or one order of magnitude larger than its real size [53]! Even if the sizes are accurate, many free-living algae harbor genomes that are bloated with repeated elements (e.g. $[54,55])$ that can propagate rapidly upon the right conditions and which have little effect on the overall metabolic profile of the species. Comparisons based on the total number of genes are therefore preferable but not necessarily accurate either. Automated gene prediction algorithms can struggle with their proper detection, sometimes grossly under- or overestimating their presence by the thousands $[55,56]$, and we lack the manpower to manually curate all of the incoming onslaught of genomic data. Furthermore, a greater gene count is not necessarily synonymous with a greater metabolic potential, as duplications have occurred many times throughout evolution. Without looking at the genes themselves, inferences about parasitic reduction, free-living expansion or a mixture of both processes cannot be made without prior knowledge of the state that was present in the common ancestor.

By glancing quickly at sizes and gene numbers alone (Fig. 4), the Helicosporidium nuclear genome (12.4 Mbp assembled; $17 \mathrm{Mbp}$ estimated [31]) appears to have shrunken down to almost a third of that of the free-living Coccomyxa (49 Mbp; [57]) and the symbiotic Chlorella (46 Mbp; [58]) and encodes a gene set that is about $40 \%$ smaller than that of its relatives. However, when looking at their respective metabolic profiles (Fig. 4), the picture that emerges is quite different. The core green algal metabolic pathways are all present in Helicosporidium and the only clear reduction has been the loss of its photosynthetic ability (Fig. 4). But even here the reduction is not complete and Helicosporidium has retained all of the genes involved in the storage of sugars as starchy polymers. The lower gene count in Helicosporidium can be attributed at least in part to the presence of fewer paralogous gene copies and to the absence of non-essential alternate metabolic branches synthesizing compounds that are either accessory or produced via other pathways. Other factors that contribute to the small size of the Helicosporidium genome are the limited number of introns, about on par 


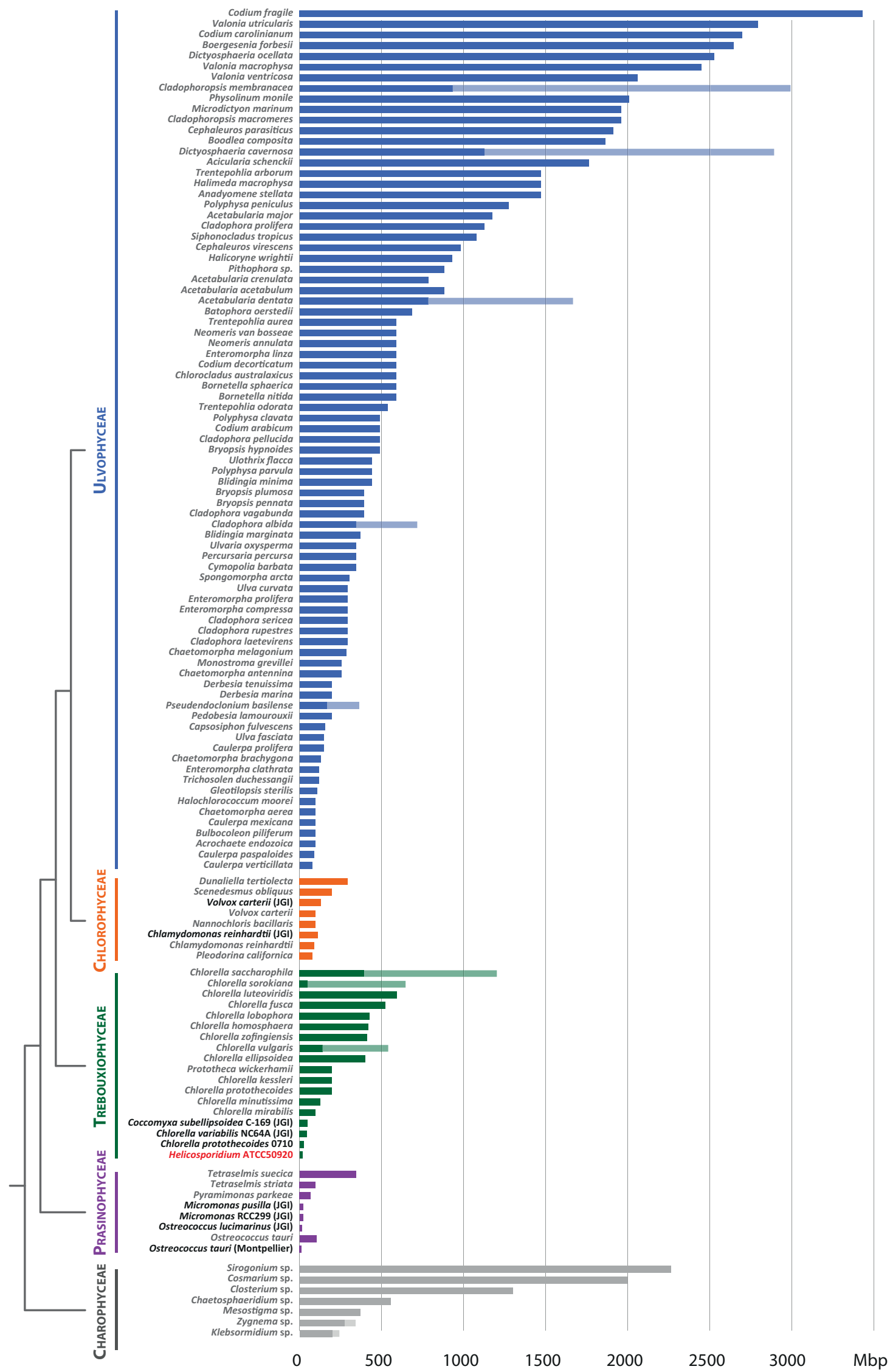

Fig. 3 Estimated green algal genome sizes in the Streptophyta and Chlorophyta. Genomes that were sequenced are lettered in black, with Helicosporidium lettered in red. Genomes whose sizes were estimated based on their 1C-values are lettered in gray. Estimated 1C-values for algae from the Streptophyta (Charophyceae) were inferred from Kapraun ([52]; only the smallest representatives were selected) whereas others from the Chlorophyta (Prasinophyceae, Trebouxiophyceae, Chlorophyceae, Ulvophyceae) were retrieved from the RBG Kew Algae DNA C-values database (http://data.kew.org/cvalues). Dark and light shades in the histogram bars correspond to lower and upper 1C-value size estimates. The histogram is color-coded according to the underlying cladogram depicting the branching order between these lineages. 


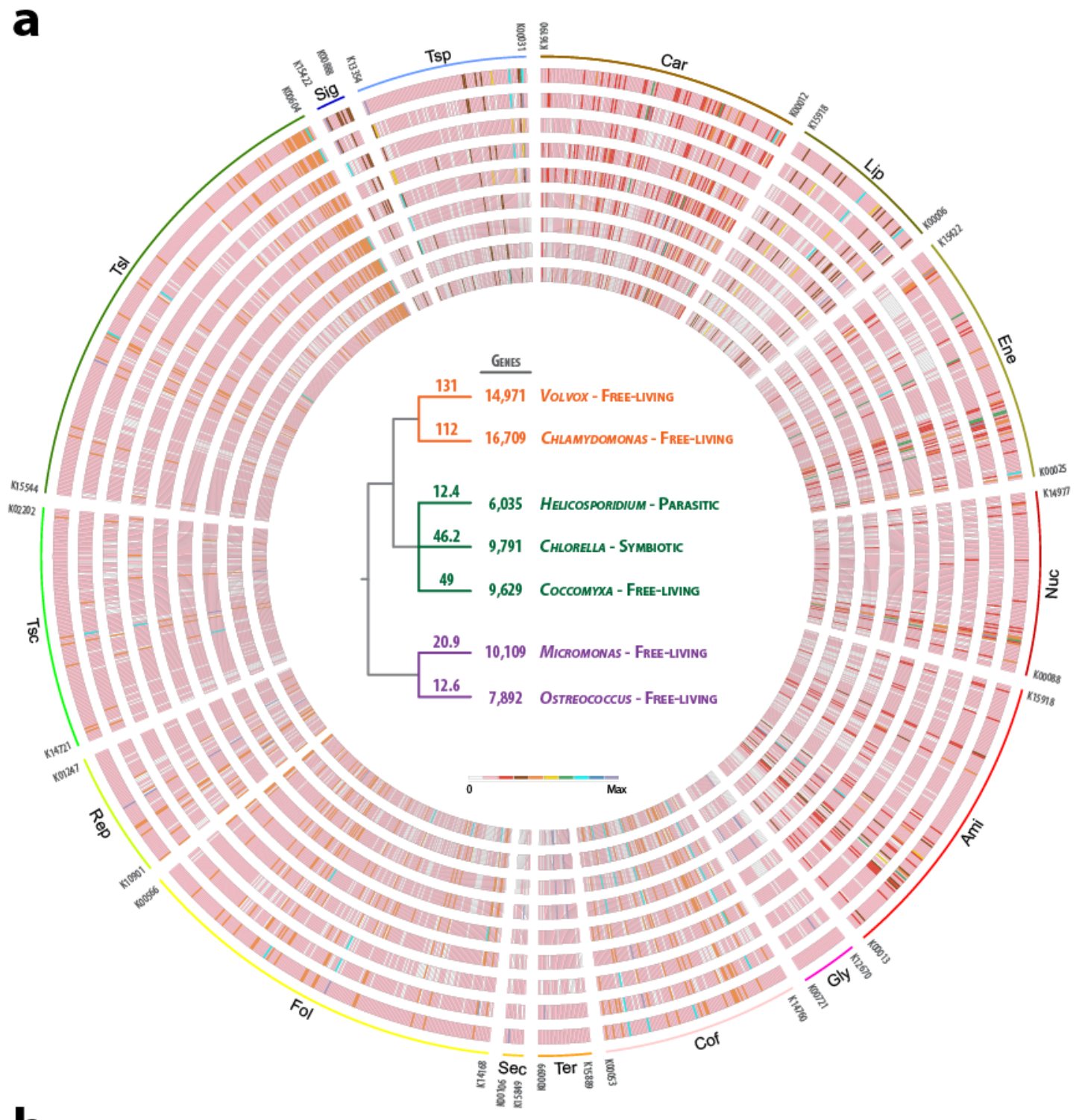

b

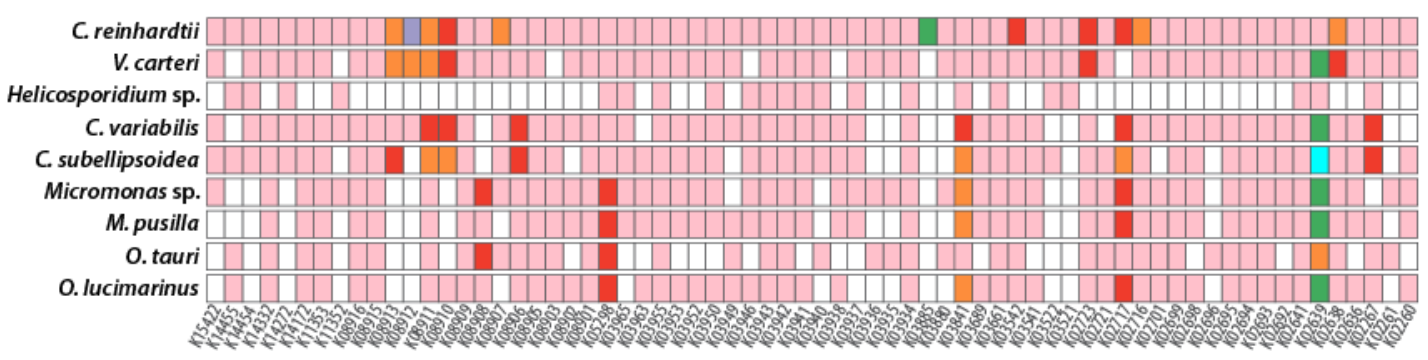

Fig. 4 Distribution of KEGG metabolic pathways among sequenced green algal nuclear genomes. a The concentric rings, from the outside to the inside, are: Chlamydomonas reinhardtii, Volvox carteri f. nagariensis, Helicosporidium sp., Chlorella variabilis NC64A, Coccomyxa subellipsoidea C-169, Micromonas sp. RCC299, Micromonas pusilla, Ostreococcus tauri, Ostreococcus lucimarinus. Each bar in the concentric rings corresponds to a unique protein in the overarching pathways. KEGG orthology identifiers (KO) indicated at the start and end of each arc correspond to the order in Tab. S1. Color gradients indicate the respective number of each protein-coding gene in the corresponding organisms. The gradient is a heat map standardized per pathway for visual balance. The absence of a proteincoding gene is indicated by a white color, whereas the pink to purple gradient (pink, red, brown, orange, gold, green, cyan, blue, purple) indicate the relative number of gene copies per pathway. The KEGG metabolic pathways are: Ami: amino acids; Car: carbohydrates; Cof: cofactors and vitamins; Ene: energy; Fol: folding, sorting and degradation; Gly: glycan; Lip: lipids; Nuc: nucleotides; Rep: replication and repair; Sec: secondary metabolites; Sig: signal transduction; Ter: terpenoids and polyketides; Tsc: transcription; Tsl; translation; Tsp; transport. The cladogram in the center schematizes the relationships between the prasinophytes (in purple), trebouxiophytes (in green) and chlorophycean algae (in orange). Assembled genome sizes (in Mbp) are indicated above the corresponding branches; values for picoprasinophytes are from Ostreococcus tauri and Micromonas sp. RCC299. b Zoom-in of the major Helicosporidium losses in the KEGG energy-related pathways. The corresponding KEGG orthology identifiers (KO) indicated under the corresponding blocks are further described in Tab. S1. 
with picoprasinophytes and roughly three times less than in the other Trebouxiophyceae and Chlorophyceae, and the dearth of transposable elements [31]. Helicosporidium lacks the Dicer and Argonaute proteins hypothesized to suppress the propagation of transposable elements (TEs) [59], and it is unclear if the RNA interference machinery was lost because its function was accessory.

So, did the Helicosporidium genome shrink over time, was it the other trebouxiophycean genomes that have expanded or perhaps a bit of both? Almost concurrently with the publication of the Helicosporidium genome, Gao and co-authors reported the genome of another free-living Trebouxiophyceae, Chlorella protothecoides, assembled at 22.9 Mbp with a maximum estimated size of 27.6 Mbp [60]. The C. protothecoides genome is also quite compact and displays features that are intermediates between the Helicosporidium and C. variabilis/Coccomyxa genomes. In particular, like Helicosporidium, multi-copy genes are fewer in $C$. protothecoides than in the other trebouxiophycean genomes, suggesting that expansion by duplication may have occurred in this lineage [60]. The variation in size observed in the Trebouxiophyceae is not limited to this lineage and all green algal classes feature a mixture of species with small, medium or large genomes (Fig. 3). The problem is that we actually don't know what the genomic state of the green algal ancestor was, but here we infer that it was likely small. The genomes of prasinophytes occupying the most basal branches of the Chlorophyta phylum tend to be on the smaller scale and, while charophycean genomes in the Streptophyta have been somewhat stigmatized as humongous (many of the early ones investigated were indeed quite large [61]), species with genomes in the $100 \mathrm{Mbp}$ range also exists [52] and, again,

\section{Acknowledgments}

This work was supported by funds from the Illinois Institute of Technology.

\section{Authors' contributions}

The following declarations about authors' contributions to the research have been made: performed the phylogenetic analysis: YS; wrote the mini-review: YS, JFP.

\section{Competing interests}

No competing interests have been declared.

\section{Supplementary material}

The following supplementary material for this article is available online at http://pbsociety.org.pl/journals/index.php/asbp/rt/suppFiles/ asbp.2014.039/0:

1. Tab S1: distribution of KEGG metabolic pathways among sequenced green algal genomes.

\section{References}

1. Walker DM, Oghumu S, Gupta G, McGwire BS, Drew ME, Satoskar AR. Mechanisms of cellular invasion by intracellular parasites. Cell Mol Life Sci. 2014;71(7):1245-1263. http://dx.doi.org/10.1007/ s00018-013-1491-1

2. Jackson AP. Genome evolution in trypanosomatid parasites. Parasitology. 2014 (in press). http://dx.doi.org/10.1017/S0031182014000894

3. Wijayawardena BK, Minchella DJ, DeWoody JA. Hosts, parasites, and horizontal gene transfer. Trends Parasitol. 2013;29(7):329-338. http:// dx.doi.org/10.1016/j.pt.2013.05.001

4. Corradi N, Selman M. Latest progress in microsporidian genome tend to branch at the base of the clade. We cannot rule out that the ancestral genome of the green algae may have been bloated and then reduced repeatedly and independently over time, but the opposite scenario is more parsimonious and thus, we find it more likely. Considering the above, we think that the Helicosporidium genome did not really experience much reduction, aside from a few clear photosynthetic and other gene losses, and that it has retained a genome whose features are probably closer to the ancestral ones than that of Coccomyxa and C. variabilis.

Our picture of the evolution of Helicosporidia is far from complete however. The Helicosporidium genome reported corresponds to the one with the shortest branch in our $18 \mathrm{~S}$ rDNA tree (Fig. 1) and may thus represent one of the less derived helicosporidians. Looking at the other species may reveal greater levels of specialization and/or host dependency and help identify the components that are important for their infection strategies. Helicosporidium sp. was found to harbor numerous chitinases that can help breach its invertebrate host gut epithelium but also featured over 850 unique predicted proteins that were found to be expressed and for which no homology was found [31]. It is unclear if these transcripts are functional or the result of transcriptional noise, but their unicity in some cases may reflect novel or derivedbeyond-recognition components potentially involved in pathogenicity. In that regard, sequencing the genomes of the closest known relatives of Helicosporidia from the genus Prototheca would most likely provide interesting insights, considering that these related species can also parasitize various hosts upon favorable conditions, potentially with the help of shared genetic components.

research. J Eukaryot Microbiol. 2013;60(3):309-312. http://dx.doi. org/10.1111/jeu.12030

5. Raffaele S, Kamoun S. Genome evolution in filamentous plant pathogens: why bigger can be better. Nat Rev Microbiol. 2012;10:417-430. http://dx.doi.org/10.1038/nrmicro2790

6. Blouin NA, Lane CE. Red algal parasites: models for a life history evolution that leaves photosynthesis behind again and again. Bioessays. 2012;34(3):226-235. http://dx.doi.org/10.1002/bies.201100139

7. Selman M, Pombert JF, Solter L, Farinelli L, Weiss LM, Keeling P, et al. Acquisition of an animal gene by microsporidian intracellular parasites. Curr Biol. 2011;21(15):R576-R577. http://dx.doi.org/10.1016/j. cub.2011.06.017

8. Pombert JF, Selman M, Burki F, Bardell FT, Farinelli L, Solter LF, et al. Gain and loss of multiple functionally related, horizontally transferred genes in the reduced genomes of two microsporidian parasites. Proc Natl Acad Sci USA. 2012;109(31):12638-12643. http://dx.doi. org/10.1073/pnas.1205020109

9. Anderson MT, Seifert HS. Opportunity and means: horizontal gene transfer from the human host to a bacterial pathogen. mBio. 2011;2(1):e00005-11. http://dx.doi.org/10.1128/mBio.00005-11

10. Kishore SP, Stiller JW, Deitsch KW. Horizontal gene transfer of epigenetic machinery and evolution of parasitism in the malaria parasite Plasmodium falciparum and other apicomplexans. BMC Evol Biol. 2013;13(1):37. http://dx.doi.org/10.1186/1471-2148-13-37

11. Lee SC, Weiss LM, Heitman J. Generation of genetic diversity in microsporidia via sexual reproduction and horizontal gene transfer. Commun Integr Biol. 2009;2(5):414-417. http://dx.doi.org/10.4161/ cib.2.5.8846

12. Weigel LM, Clewell DB, Gill SR, Clark NC, McDougal LK, Flannagan 
SE, et al. Genetic analysis of a high-level vancomycin-resistant isolate of Staphylococcus aureus. Science. 2003;302(5650):1569-1571. http:// dx.doi.org/10.1126/science.1090956

13. Nakabachi A, Nikoh N, Oshima K, Inoue H, Ohkuma M, Hongoh Y, et al. Horizontal gene acquisition of Liberibacter plant pathogens from a bacteriome-confined endosymbiont of their psyllid vector. PLoS ONE. 2013;8(12):e82612. http://dx.doi.org/10.1371/journal.pone.0082612

14. Grant JR, Katz LA. Phylogenomic study indicates widespread lateral gene transfer in Entamoeba and suggests a past intimate relationship with parabasalids. Genome Biol Evol. 2014;6(9):2350-2360. http:// dx.doi.org/10.1093/gbe/evu179

15. Richards TA, Soanes DM, Jones MDM, Vasieva O, Leonard G, Paszkiewicz K, et al. Horizontal gene transfer facilitated the evolution of plant parasitic mechanisms in the oomycetes. Proc Natl Acad Sci USA. 2011;108(37):15258-15263. http://dx.doi.org/10.1073/ pnas. 1105100108

16. Gardiner DM, Kazan K, Manners JM. Cross-kingdom gene transfer facilitates the evolution of virulence in fungal pathogens. Plant Sci. 2013;210:151-158. http://dx.doi.org/10.1016/j.plantsci.2013.06.002

17. Soanes D, Richards TA. Horizontal gene transfer in eukaryotic plant pathogens. Annu Rev Phytopathol. 2014;52(1):583-614. http://dx.doi. org/10.1146/annurev-phyto-102313-050127

18. Slamovits CH, Fast NM, Law JS, Keeling PJ. Genome compaction and stability in microsporidian intracellular parasites. Curr Biol. 2004;14(10):891-896. http://dx.doi.org/10.1016/j.cub.2004.04.041

19. Cuomo CA, Desjardins CA, Bakowski MA, Goldberg J, Ma AT, Becnel $\mathrm{JJ}$, et al. Microsporidian genome analysis reveals evolutionary strategies for obligate intracellular growth. Genome Res. 2012;22(12):2478-2488. http://dx.doi.org/10.1101/gr.142802.112

20. Burki F, Corradi N, Sierra R, Pawlowski J, Meyer GR, Abbott CL, et al. Phylogenomics of the intracellular parasite Mikrocytos mackini reveals evidence for a mitosome in rhizaria. Curr Biol. 2013;23(16):1541-1547. http://dx.doi.org/10.1016/j.cub.2013.06.033

21. Rich SM, Xu G. Resolving the phylogeny of malaria parasites. Proc Natl Acad Sci USA. 2011;108(32):12973-12974. http://dx.doi.org/10.1073/ pnas. 1110141108

22. Keeling P. Five questions about microsporidia. PLoS Pathog. 2009;5(9):e1000489. http://dx.doi.org/10.1371/journal.ppat.1000489

23. Keilin D. On the life-history of Helicosporidium parasiticum, n.g., n.sp., a new type of protist parasitic in the larva of Dasyhelea obscura Winn. (Diptera, Ceratopogonidae) and in some other arthropods. Parasitology. 1921;13(02):97. http://dx.doi.org/10.1017/S003118200001235X

24. Boucias DG, Becnel JJ, White SE, Bott M. In vivo and in vitro development of the protist Helicosporidium sp. J Eukaryot Microbiol. 2001;48(4):460-470. http://dx.doi.org/10.1111/j.1550-7408.2001. tb00180.x

25. Tartar A, Boucias DG, Adams BJ, Becnel JJ. Phylogenetic analysis identifies the invertebrate pathogen Helicosporidium sp. as a green alga (Chlorophyta). Int J Syst Evol Microbiol. 2002;52(1):273-279.

26. Tartar A, Boucias DG, Becnel JJ, Adams BJ. Comparison of plastid $16 \mathrm{~S}$ rRNA (rrn16) genes from Helicosporidium spp.: evidence supporting the reclassification of Helicosporidia as green algae (Chlorophyta). Int J Syst Evol Microbiol. 2003;53(6):1719-1723. http://dx.doi.org/10.1099/ ijs.0.02559-0

27. de Koning AP, Keeling PJ. The complete plastid genome sequence of the parasitic green alga Helicosporidium sp. is highly reduced and structured. BMC Biol. 2006;4(1):12. http://dx.doi. org/10.1186/1741-7007-4-12

28. Pombert JF, Keeling PJ. The mitochondrial genome of the entomoparasitic green alga Helicosporidium. PLoS ONE. 2010;5(1):e8954. http://dx.doi.org/10.1371/journal.pone.0008954

29. de Koning AP, Keeling PJ. Nucleus-encoded genes for plastid-targeted proteins in Helicosporidium: functional diversity of a cryptic plastid in a parasitic alga. Eukaryot Cell. 2004;3(5):1198-1205. http://dx.doi. org/10.1128/EC.3.5.1198-1205.2004

30. de Koning A. Expressed sequence tag (EST) survey of the highly adapted green algal parasite, Helicosporidium. Protist. 2005;156(2):181190. http://dx.doi.org/10.1016/j.protis.2005.02.005

31. Pombert JF, Blouin NA, Lane C, Boucias D, Keeling PJ. A lack of parasitic reduction in the obligate parasitic green alga Helicosporidium. PLoS Genet. 2014;10(5):e1004355. http://dx.doi.org/10.1371/journal. pgen.1004355

32. Tartar A. The non-photosynthetic algae Helicosporidium spp.: emergence of a novel group of insect pathogens. Insects. 2013;4(3):375-391. http://dx.doi.org/10.3390/insects4030375

33. Leliaert F, Smith DR, Moreau H, Herron MD, Verbruggen H, Delwiche $\mathrm{CF}$, et al. Phylogeny and molecular evolution of the green algae. Crit Rev Plant Sci. 2012;31(1):1-46. http://dx.doi.org/10.1080/07352689 .2011 .615705

34. Lass-Florl C, Mayr A. Human protothecosis. Clin Microbiol Rev. 2007;20(2):230-242. http://dx.doi.org/10.1128/CMR.00032-06

35. de Wever A, Leliaert F, Verleyen E, Vanormelingen P, van der Gucht K, Hodgson DA, et al. Hidden levels of phylodiversity in Antarctic green algae: further evidence for the existence of glacial refugia. Proc Biol Sci. 2009;276(1673):3591-3599. http://dx.doi.org/10.1098/rspb.2009.0994

36. Hedges SB. The origin and evolution of model organisms. Nat Rev Genet. 2002;3(11):838-849. http://dx.doi.org/10.1038/nrg929

37. Escalante AA, Ayala FJ. Evolutionary origin of Plasmodium and other Apicomplexa based on rRNA genes. Proc Natl Acad Sci USA. 1995;92(13):5793-5797. http://dx.doi.org/10.1073/pnas.92.13.5793

38. Gardner MJ, Hall N, Fung E, White O, Berriman M, Hyman RW, et al. Genome sequence of the human malaria parasite Plasmodium falciparum. Nature. 2002;419(6906):498-511. http://dx.doi.org/10.1038/ nature01097

39. McFadden GI, Reith ME, Munholland J, Lang-Unnasch N. Plastid in human parasites. Nature. 1996;381(6582):482-482. http://dx.doi. org/10.1038/381482a0

40. Kohler S. A plastid of probable green algal origin in apicomplexan parasites. Science. 1997;275(5305):1485-1489. http://dx.doi.org/10.1126/ science. 275.5305 .1485

41. Lim L, McFadden GI. The evolution, metabolism and functions of the apicoplast. Philos Trans R Soc Lond B Biol Sci. 2010;365(1541):749763. http://dx.doi.org/10.1098/rstb.2009.0273

42. Nair SC, Striepen B. What do human parasites do with a chloroplast anyway? PLoS Biol. 2011;9(8):e1001137. http://dx.doi.org/10.1371/ journal.pbio.1001137

43. Mayorga J, Barba-Gómez JF, Verduzco-Martínez AP, Muñoz-Estrada VF, Welsh O. Protothecosis. Clin Dermatol. 2012;30(4):432-436. http:// dx.doi.org/10.1016/j.clindermatol.2011.09.016

44. Knauf U, Hachtel W. The genes encoding subunits of ATP synthase are conserved in the reduced plastid genome of the heterotrophic alga Prototheca wickerhamii. Mol Genet Genomics. 2002;267(4):492-497. http://dx.doi.org/10.1007/s00438-002-0681-6

45. Makiuchi T, Nozaki T. Highly divergent mitochondrion-related organelles in anaerobic parasitic protozoa. Biochimie. 2014;100:3-17. http://dx.doi.org/10.1016/j.biochi.2013.11.018

46. Martin WF, Müller M. Origin of mitochondria and hydrogenosomes. New York, NY: Springer; 2007.

47. Goldberg AV, Molik S, Tsaousis AD, Neumann K, Kuhnke G, Delbac $\mathrm{F}$, et al. Localization and functionality of microsporidian iron-sulphur cluster assembly proteins. Nature. 2008;452(7187):624-628. http:// dx.doi.org/10.1038/nature06606

48. Vávra J, Lukeš J. Microsporidia and "the art of living together". In: Rollinson D, editor. . New York, NY: Elsevier; 2013. p. 253-319. (vol 82).

49. Schneider RE, Brown MT, Shiflett AM, Dyall SD, Hayes RD, Xie $\mathrm{Y}$, et al. The Trichomonas vaginalis hydrogenosome proteome is highly reduced relative to mitochondria, yet complex compared with mitosomes. Int J Parasitol. 2011;41(13-14):1421-1434. http://dx.doi. org/10.1016/j.ijpara.2011.10.001

50. Smith DR, Hamaji T, Olson BJSC, Durand PM, Ferris P, Michod RE, et al. Organelle genome complexity scales positively with organism size in volvocine green algae. Mol Biol Evol. 2013;30(4):793-797. http://dx.doi.org/10.1093/molbev/mst002

51. Pombert JF, Otis C, Turmel M, Lemieux C. The mitochondrial genome of the prasinophyte Prasinoderma coloniale reveals two transspliced group I introns in the large subunit rRNA gene. PLoS ONE. 2013;8(12):e84325. http://dx.doi.org/10.1371/journal.pone.0084325 
52. Kapraun DF. Nuclear DNA content estimates in green algal lineages: Chlorophyta and Streptophyta. Ann Bot. 2006;99(4):677-701. http:// dx.doi.org/10.1093/aob/mcl294

53. Derelle E, Ferraz C, Rombauts S, Rouze P, Worden AZ, Robbens $\mathrm{S}$, et al. Genome analysis of the smallest free-living eukaryote Ostreococcus tauri unveils many unique features. Proc Natl Acad Sci USA. 2006;103(31):11647-11652. http://dx.doi.org/10.1073/ pnas.0604795103

54. Prochnik SE, Umen J, Nedelcu AM, Hallmann A, Miller SM, Nishii I, et al. Genomic analysis of organismal complexity in the multicellular green alga Volvox carteri. Science. 2010;329(5988):223-226. http:// dx.doi.org/10.1126/science. 1188800

55. Godman J, Balk J. Genome analysis of Chlamydomonas reinhardtii reveals the existence of multiple, compartmentalized iron-sulfur protein assembly machineries of different evolutionary origins. Genetics. 2008;179(1):59-68. http://dx.doi.org/10.1534/genetics.107.086033

56. Yandell M, Ence D. A beginner's guide to eukaryotic genome annotation. Nat Rev Genet. 2012;13(5):329-342. http://dx.doi.org/10.1038/ nrg3174

57. Blanc G, Agarkova I, Grimwood J, Kuo A, Brueggeman A, Dunigan $\mathrm{DD}$, et al. The genome of the polar eukaryotic microalga Coccomyxa subellipsoidea reveals traits of cold adaptation. Genome Biol. 2012;13(5):R39. http://dx.doi.org/10.1186/gb-2012-13-5-r39
58. Blanc G, Duncan G, Agarkova I, Borodovsky M, Gurnon J, Kuo A, et al. The Chlorella variabilis NC64A genome reveals adaptation to photosymbiosis, coevolution with viruses, and cryptic sex. Plant Cell. 2010;22(9):2943-2955. http://dx.doi.org/10.1105/tpc.110.076406

59. Chung WJ, Okamura K, Martin R, Lai EC. Endogenous RNA interference provides a somatic defense against Drosophila transposons. Curr Biol. 2008;18(11):795-802. http://dx.doi.org/10.1016/j.cub.2008.05.006

60. Gao C, Wang Y, Shen Y, Yan D, He X, Dai J, et al. Oil accumulation mechanisms of the oleaginous microalga Chlorella protothecoides revealed through its genome, transcriptomes, and proteomes. BMC Genomics. 2014;15(1):582. http://dx.doi.org/10.1186/1471-2164-15-582

61. Kapraun DF. Nuclear DNA content estimates in multicellular green, red and brown algae: phylogenetic considerations. Ann Bot. 2005;95(1):744. http://dx.doi.org/10.1093/aob/mci002

62. Guindon S, Dufayard JF, Lefort V, Anisimova M, Hordijk W, Gascuel O. New algorithms and methods to estimate maximum-likelihood phylogenies: assessing the performance of PhyML 3.0. Syst Biol. 2010;59(3):307-321. http://dx.doi.org/10.1093/sysbio/syq010

63. Gouy M, Guindon S, Gascuel O. SeaView version 4: a multiplatform graphical user interface for sequence alignment and phylogenetic tree building. Mol Biol Evol. 2010;27(2):221-224. http://dx.doi. org/10.1093/molbev/msp259 